Article

\title{
On a Common Jungck Type Fixed Point Result in Extended Rectangular b-Metric Spaces
}

\author{
Hassen Aydi 1,2®, Zoran D. Mitrović ${ }^{3}$, Stojan Radenović ${ }^{4}$ and Manuel de la Sen ${ }^{5, *}$ \\ 1 Institut Supérieur d'Informatique et des Techniques de Communication, H. Sousse, Université de Sousse, \\ Sousse 4000, Tunisia; hassen.aydi@isima.rnu.tn \\ 2 China Medical University Hospital, China Medical University, Taichung 40402, Taiwan \\ 3 Faculty of Electrical Engineering, University of Banja Luka, Patre 5, 78000 Banja Luka, \\ Bosnia and Herzegovina; zoran.mitrovic@etf.unibl.org \\ 4 Faculty of Mechanical Engineering, University of Belgrade, Kraljice Marije 16, 11120 Beograd, Serbia; \\ radens@beotel.rs \\ 5 Institute of Research and Development of Processes IIDP, University of the Basque Country, \\ 48940 Bizkaia, Spain \\ * Correspondence: manuel.delasen@ehu.eus
}

Received: 10 December 2019; Accepted: 24 December 2019; Published: 27 December 2019

\begin{abstract}
In this paper, we present a Jungck type common fixed point result in extended rectangular b-metric spaces. We also give some examples and a known common fixed point theorem in extended b-metric spaces.
\end{abstract}

Keywords: fixed points; common fixed points; extended rectangular b-metric space

\section{Introduction}

The notion of b-metric spaces was first introduced by Bakhtin [1] and Czerwik [2]. This metric type space has been generalized in several directions. Among of them, we may cite, extended b-metric spaces [3], controlled metric spaces [4] and double controlled metric spaces [5]. Within another vision, Branciari [6] initiated rectangular metric spaces. In same direction, Asim et al. [7] included a control function to initiate the concept of extended rectangular b-metric spaces, as a generalization of rectangular b-metric spaces [8].

Definition 1 ([7]). Let $X$ be a nonempty set and $e: X \times X \rightarrow[1, \infty)$ be a function. If $d_{e}: X \times X \rightarrow[0, \infty)$ is such that

$$
\begin{aligned}
& (E R b M 1) d_{e}(\omega, \Omega)=0 \text { iff } \omega=\Omega ; \\
& (E R b M 2) d_{e}(\omega, \Omega)=d_{e}(\Omega, \omega) \\
& (E R b M 3) d_{e}(\omega, \Omega) \leq e(\omega, \Omega)\left[d_{e}(\omega, \zeta)+d_{e}(\zeta, \sigma)+d_{e}(\sigma, \Omega)\right]
\end{aligned}
$$

for all $\omega, \Omega \in X$ and all distinct elements $\zeta, \sigma \in X \backslash\{\omega, \Omega\}$, then $d_{e}$ is an extended rectangular $b$-metric on $X$ with mapping $e$.

Definition 2 ([7]). Let $\left(X, d_{e}\right)$ be an extended rectangular b-metric space, $\left\{\Omega_{n}\right\}$ be a sequence in $X$ and $\Omega \in X$.

(a) $\left\{\Omega_{n}\right\}$ converges to $\Omega$, if for each $\tau>0$ there is $n_{0} \in \mathbb{N}$ so that $d_{e}\left(\Omega_{n}, \Omega\right)<\tau$ for any $n>n_{0}$. We write it as $\lim _{n \rightarrow \infty} \Omega_{n}=\Omega$ or $\Omega_{n} \rightarrow \Omega$ as $n \rightarrow \infty$.

(b) $\left\{\Omega_{n}\right\}$ is Cauchy if for each $\tau>0$ there is $n_{0} \in \mathbb{N}$ so that $d_{e}\left(\Omega_{n}, \Omega_{n+p}\right)<\tau$ for any $n>n_{0}$ and $p>0$. 
(c) $(X, d)$ is complete if each Cauchy sequence is convergent.

Note that the topology of rectangular metric spaces need not be Hausdorff. For more examples, see the papers of Sarma et al. [9] and Samet [10]. The topological structure of rectangular metric spaces is not compatible with the topology of classic metric spaces, see Example 7 in the paper of Suzuki [11]. Going in same direction, extended rectangular b-metric spaces can not be Hausdorff. The following example (a variant of Example 1.7 of George et al. [8]) explains this fact.

Example 1. Let $X=\Gamma_{1} \cup \Gamma_{2}$, where $\Gamma_{1}=\left\{\frac{1}{n}, n \in \mathbb{N}\right\}$ and $\Gamma_{2}$ is the set of all positive integers. Define $d_{e}$ : $X \times X \rightarrow[0, \infty)$ so that $d_{e}$ is symmetric and for all $\Omega, \omega \in X$,

$$
d_{e}(\Omega, \omega)= \begin{cases}0, & \text { if } \Omega=\omega, \\ 8, & \text { if } \Omega, \omega \in \Gamma_{1}, \\ \frac{2}{n}, & \text { if } \Omega \in \Gamma_{1} \text { and } \omega \in\{2,3\} \\ 4 & \text { otherwise. }\end{cases}
$$

Here, $\left(X, d_{e}\right)$ is an extended rectangular b-metric space with $e(\Omega, \omega)=2$. Note that there exist no $\tau_{1}, \tau_{2}>0$ such that $B_{\tau_{1}}(2) \cap B_{\tau_{2}}(3)=\varnothing$ (where $B_{x}(\tau)$ denotes the ball of center $x$ and radius $\tau$ ). That is, $\left(X, d_{e}\right)$ is not Hausdorff.

The main result of Jungck [12] is following.

Theorem 1 ([12]). If $f$ and $H$ are commuting self-maps on a complete metric space $(X, d)$ such that $f(X) \subseteq H(X), H$ is continuous and

$$
d(f \Omega, f \omega) \leq \delta d(H \Omega, H \omega)
$$

for all $\Omega, \omega \in X$, where $0<\delta<1$, then there is a unique common fixed point of $f$ and $H$.

Our goal is to get the analogue of Theorem 1 in the setting of extended rectangular b-metric spaces. Some examples are also provided.

\section{Main Results}

Definition 3. Let $X$ be a nonempty set and $f, H$ be two commuting self-mappings of $X$ so that $f(X) \subseteq H(X)$. Then $(f, H)$ is called a Jungck pair of mappings on $X$.

Example 2. Let $X=\mathbb{R} \times \mathbb{R}$. Define $f, H: X \rightarrow X$ by $f(\omega, \Omega)=(2 \omega,(\Omega / 2)+3)$ and $H(\omega, \Omega)=$ $(3 \omega,(\Omega / 3)+4)$. Then $f(H(\omega, \Omega))=(6 \omega,(\Omega / 6)+5)=H(f(\omega, \Omega))$, so that $(f, H)$ is a Jungck pair of mappings on $X$.

Lemma 1. Let $X$ be a nonempty set and $(f, H)$ be a Jungck pair of mappings on $X$. Given $\Omega_{0} \in X$. Then there is a sequence $\left\{\Omega_{n}\right\}$ in $X$ so that $H \Omega_{n+1}=f \Omega_{n}, n \geq 0$.

Proof. For such $\Omega_{0} \in X, f \Omega_{0}$ and $H \Omega_{0}$ are well defined. Since $f \Omega_{0} \in H(X)$, there is $\Omega_{1} \in X$ so that $H \Omega_{1}=f \Omega_{0}$. Going in same direction, we arrive to $H \Omega_{n+1}=f \Omega_{n}$.

Definition 4. Let $(f, H)$ be a Jungck pair of mappings on a nonempty set $X$. Given $e: X \times X \rightarrow[1, \infty)$. Let $\left\{\Omega_{n}\right\}$ be a sequence such that $H \Omega_{n+1}=f \Omega_{n}$, for each $n \geq 0$. Then $\left\{\Omega_{n}\right\}$ is called $a(f, H)$ Jungck sequence in X. We say that $\left\{\Omega_{n}\right\}$ is e-bounded if $\limsup _{n, m \rightarrow \infty} e\left(H \Omega_{n}, H \Omega_{m}\right)<\infty$. 


\section{Remark 1.}

1. If $H=i d$, $(i d(\omega)=\omega, \omega \in X)$ then $a(f, i d)$ Jungck sequence is a Picard sequence.

2. Note that each sequence in a rectangular b-metric space with coefficient $s \geq 1$ (see [8]) is e-bounded $\left(e\left(\Omega_{m}, \Omega_{n}\right)=s\right.$, for all $\left.m, n \in \mathbb{N}\right)$.

Theorem 2. Let $(f, H)$ be a Jungck pair of mappings on a complete extended rectangular b-metric space $\left(X, d_{e}\right)$ so that

$$
d_{e}(f \Omega, f \omega) \leq \rho d_{e}(H \Omega, H \omega),
$$

for all $\Omega, \omega \in X$, where $0<\rho<1$. If $H$ is continuous and there is an e-bounded $(f, H)$ Jungck sequence, then there is a unique common fixed point of $f$ and $H$.

Proof. Let $\left\{\Omega_{n}\right\}$ be an $e$-bounded $(f, H)$ Jungck sequence. Then for $\Omega_{0} \in X, f \Omega_{n+1}=H \Omega_{n}$, for each $n \geq 0$. We show that $\left\{f \Omega_{n}\right\}$ is Cauchy. From (2), we have

$$
\begin{aligned}
d_{e}\left(H \Omega_{m+k}, H \Omega_{n+k}\right) & =d_{e}\left(f \Omega_{m+k-1}, f \Omega_{n+k-1}\right) \\
& \leq \rho d_{e}\left(H \Omega_{m+k-1}, H \Omega_{n+k-1}\right) .
\end{aligned}
$$

So,

$$
d_{e}\left(H \Omega_{m+k}, H \Omega_{n+k}\right) \leq \rho^{k} d_{e}\left(H \Omega_{m}, H \Omega_{n}\right),
$$

for each $k \in \mathbb{N}$.

\section{Case 1:}

If $H \Omega_{n}=H \Omega_{n+1}$ for some $n$, define $\theta:=f \Omega_{n}=H \Omega_{n}$. We claim that $f \theta=H \theta=\theta$ and $\theta$ is unique. First,

$$
f \theta=f H \Omega_{n}=H f \Omega_{n}=H \theta .
$$

Let $d_{e}(\theta, f \theta)>0$. Here,

$$
\begin{aligned}
d_{e}(\theta, f \theta) & =d_{e}\left(f \Omega_{n}, f \theta\right) \\
& \leq \rho d_{e}\left(H \Omega_{n}, H \theta\right) \\
& =\rho d_{e}(\theta, H \theta) \\
& =\rho d_{e}(\theta, f \theta) \\
& <d_{e}(\theta, f \theta),
\end{aligned}
$$

which is a contradiction. Recall that (2) yields that $f \Omega_{n}=H \Omega_{n}=\theta$ is the unique common fixed point of $f$ and $H$.

\section{Case 2:}

If $H \Omega_{n} \neq H \Omega_{n+1}$ for all $n \geq 0$, then $H \Omega_{n} \neq H \Omega_{n+k}$ for all $n \geq 0$ and $k \geq 1$. Namely, if $H \Omega_{n}=$ $H \Omega_{n+k}$ for some $n \geq 0$ and $k \geq 1$, we have that

$$
\begin{aligned}
d_{e}\left(H \Omega_{n+1}, H \Omega_{n+k+1}\right) & =d_{e}\left(f \Omega_{n}, f \Omega_{n+k}\right) \\
& \leq \rho d_{e}\left(H \Omega_{n}, H \Omega_{n+k}\right) \\
& =0
\end{aligned}
$$

So, $H \Omega_{n+1}=H \Omega_{n+k+1}$. Then (3) implies that

$$
d_{e}\left(H \Omega_{n+1}, H \Omega_{n}\right)=d_{e}\left(H \Omega_{n+k+1}, H \Omega_{n+k}\right) \leq \rho^{k} d_{e}\left(H \Omega_{n+1}, H \Omega_{n}\right)<d_{e}\left(H \Omega_{n+1}, H \Omega_{n}\right) .
$$


It is a contradiction. Thus we assume that $H \Omega_{n} \neq H \Omega_{m}$ for all integers $n \neq m$. Note that $H \Omega_{m+k} \neq H \Omega_{n+k}$ for any $k \in \mathbb{N}$. Also, $H \Omega_{n+k}, H \Omega_{m+k} \in X \backslash\left\{H \Omega_{n}, H \Omega_{m}\right\}$. Since $\left(X, d_{e}\right)$ is an extended rectangular b-metric space, by (ERbM3), we get

$$
\begin{aligned}
d_{e}\left(H \Omega_{m}, H \Omega_{n}\right) & \leq e\left(H \Omega_{m}, H \Omega_{n}\right)\left[d_{e}\left(H \Omega_{m}, H \Omega_{m+n_{0}}\right)+d_{e}\left(H \Omega_{m+n_{0}}, H \Omega_{n+n_{0}}\right)\right. \\
& \left.+d_{e}\left(H \Omega_{n+n_{0}}, H \Omega_{n}\right)\right]
\end{aligned}
$$

where $n_{0} \in \mathbb{N}$ so that $\lim \sup _{n, m \rightarrow \infty} e\left(H \Omega_{m}, H \Omega_{n}\right)<\frac{1}{\rho^{n} 0}$. Then

$$
\begin{aligned}
d_{e}\left(H \Omega_{m}, H \Omega_{n}\right) & \leq e\left(H \Omega_{m}, H \Omega_{n}\right)\left[\rho^{m} d_{e}\left(H \Omega_{0}, H \Omega_{n_{0}}\right)+\rho^{n_{0}} d_{e}\left(H \Omega_{m}, H \Omega_{n}\right)\right. \\
& \left.+\rho^{n} d_{e}\left(H \Omega_{0}, H \Omega_{n_{0}}\right)\right]
\end{aligned}
$$

So,

$$
\left(1-e\left(H \Omega_{m}, H \Omega_{n}\right) \rho^{n_{0}}\right) d_{e}\left(H \Omega_{m}, H \Omega_{n}\right) \leq e\left(H \Omega_{m}, H \Omega_{n}\right)\left(\rho^{m}+\rho^{n}\right) d_{e}\left(H \Omega_{0}, H \Omega_{n_{0}}\right) .
$$

From this, we obtain

$$
d_{e}\left(H \Omega_{m}, H \Omega_{n}\right) \leq \frac{e\left(H \Omega_{m}, H \Omega_{n}\right)\left(\rho^{m}+\rho^{n}\right)}{1-e\left(H \Omega_{m}, H \Omega_{n}\right) \rho^{n_{0}}} d_{e}\left(H \Omega_{0}, H \Omega_{n_{0}}\right) .
$$

Thus $\left\{H \Omega_{n}\right\}$ is Cauchy in $H(X)$, which is complete, so there is $u \in X$ so that

$$
\lim _{n \rightarrow \infty} H \Omega_{n}=\lim _{n \rightarrow \infty} f \Omega_{n-1}=u .
$$

The continuity of $H$ together with (2) implies that $f$ is itself continuous. The commutativity of $f$ and $H$ leads to

$$
H u=H\left(\lim _{n \rightarrow \infty} f \Omega_{n}\right)=\lim _{n \rightarrow \infty} H f \Omega_{n}=\lim _{n \rightarrow \infty} f H \Omega_{n}=f\left(\lim _{n \rightarrow \infty} H \Omega_{n}\right)=f u .
$$

Let $v=H u=f u$. Then

$$
f v=f H u=H f u=H v \text {. }
$$

If $f u \neq f v$, by (2) we find that

$$
\begin{aligned}
d_{e}(f u, f v) & \leq \rho d_{e}(H u, H v) \\
& =\rho d_{e}(f u, f v) \\
& <d_{e}(f u, f v) .
\end{aligned}
$$

It is a contradiction, hence $f u=f v$. Thus,

$$
f v=H v=v .
$$

Condition (2) yields that $v$ is the unique common fixed point.

Example 3. If we take in Example 3.1. of [7], $H=$ id and $f$ as

$$
f 1=f 2=f 3=f 4=2 \text { and } f 5=1,
$$

then all the other conditions of Theorem 2 are satisfied, and so $f$ and $H$ have a unique fixed point, which is, $\theta=2$. Here, the space $\left(X, d_{e}\right)$ is extended rectangular b-metric space, but it is not extended b-metric space. Hence Theorem 2 generalizes, compliments and improves several known results in existing literature. 
A variant of Banach theorem in extended rectangular b-metric spaces is given as follows.

Theorem 3. Let $\left(X, d_{e}\right)$ be a complete extended rectangular b-metric space and $f: X \rightarrow X$ be so that

$$
d_{e}(f \Omega, f \omega) \leq \rho d_{e}(\Omega, \omega)
$$

for all $\Omega, \omega \in X$, where $\rho \in[0,1)$. If there is an e-bounded Picard sequence in $X$, then $f$ has a unique fixed point.

Remark 2. Theorem 3.1 in [7] is a consequence of Theorem 3. Indeed, instead of condition $\lim _{n, m \rightarrow \infty} d_{e}\left(\Omega_{n}, \Omega_{m}\right)<\frac{1}{\rho}$ of Theorem 3.1 in [7], we used a weaker condition, that is, lim sup $d_{e}\left(\Omega_{n}, \Omega_{m}\right)<\infty$.

\section{A Jungck Theorem in Extended b-Metric Spaces}

Let $\left(X, d_{e}\right)$ be an extended b-metric space (see Definition 3 in [3]) and $\left\{\Omega_{n}\right\}$ be a $(f, H) e$-bounded Jungck sequence in $X$. Then

$$
\begin{aligned}
d_{e}\left(H \Omega_{m}, H \Omega_{n}\right) \leq & e\left(H \Omega_{m}, H \Omega_{n}\right)\left[d_{e}\left(H \Omega_{m}, H \Omega_{m+n_{0}}\right)+d_{e}\left(H \Omega_{m+n_{0}}, H \Omega_{n}\right)\right] \\
\leq & e\left(H \Omega_{m}, H \Omega_{n}\right)\left[d_{e}\left(H \Omega_{m}, H \Omega_{m+n_{0}}\right)+\right. \\
& \left.e\left(H \Omega_{m+n_{0}}, H \Omega_{n}\right)\left[d_{e}\left(H \Omega_{m+n_{0}}, H \Omega_{n+n_{0}}\right)+d_{e}\left(H \Omega_{n+n_{0}}, H \Omega_{n}\right)\right]\right] \\
\leq & e\left(H \Omega_{m}, H \Omega_{n}\right) e\left(H \Omega_{m+n_{0}}, H \Omega_{n}\right)\left[d_{e}\left(H \Omega_{m}, H \Omega_{m+n_{0}}\right)+\right. \\
& \left.d_{e}\left(H \Omega_{m+n_{0}}, H \Omega_{n+n_{0}}\right)+d_{e}\left(H \Omega_{n+n_{0}}, H \Omega_{n}\right)\right] .
\end{aligned}
$$

Since $\left\{\Omega_{n}\right\}$ is a $(f, H)$ e-bounded Jungck sequence, we find that

$$
\lim \sup _{m, n \rightarrow \infty} e\left(H \Omega_{m}, H \Omega_{n}\right) e\left(H \Omega_{m+n_{0}}, H \Omega_{n}\right)<\infty .
$$

By Theorem 2, we obtain the following.

Theorem 4. Let $(f, H)$ be a Jungck pair of mappings on a complete extended b-metric space $\left(X, d_{e}\right)$ so that

$$
d_{e}(f \Omega, f \omega) \leq \rho d_{e}(H \Omega, H \omega),
$$

for all $\Omega, \omega \in X$, where $0<\rho<1$. If $H$ is continuous and there is an e-bounded $(f, H)$ Jungck sequence, then $f$ and $H$ have a unique common fixed point.

Remark 3. By Theorem 4, we obtain the Banach contraction principle in extended b-metric spaces. It improves Theorem 2.1 in [13], Theorem 2 in [3] and Theorem 2.1 in [14]. Also Theorem 3 generalizes an open problem raised by George et al. [8].

Example 4. Let $X=[0, \infty)$, e $: X \times X \rightarrow[1, \infty)$. Consider $d_{e}: X \times X \rightarrow[0, \infty)$ as

$$
d_{e}(\Omega, \omega)=(\Omega-\omega)^{2}
$$

where $e(\Omega, \omega)=\Omega+\omega+2$. Then $\left(X, d_{e}\right)$ is an extended b-metric space. Define $f \Omega=\frac{3 \Omega}{4}$. Then (8) holds for $\rho=\frac{9}{16}$. Let $\Omega_{0} \in X$ and $\Omega_{n}=f^{n} \Omega_{0}, n \in \mathbb{N}$. Then $\lim _{m, n \rightarrow \infty} e\left(\Omega_{m}, \Omega_{n}\right)=2$. So, $\lim _{m, n \rightarrow \infty} e\left(\Omega_{m}, \Omega_{n}\right)>\frac{16}{9}$ and Theorem 3.1 in [7] is not applicable. Applying Theorem 3, we conclude that $f$ has a unique fixed point.

Author Contributions: All authors contributed equally and significantly in writing this paper. All authors have read and agreed to the published version of the manuscript.

Funding: This work has been partially supported by Basque Governmnet through Grant IT1207-19.

Conflicts of Interest: The authors declare no conflict of interest. 


\section{References}

1. Bakhtin, I.A. The contraction mapping principle in quasimetric spaces. Funct. Anal. Ulianowsk Gos. Ped. Inst. 1989, 3, 26-37.

2. Czerwik, S. Contraction mappings in b-metric spaces. Acta Math. Inform. Univ. Ostrav. 1993, 1, 5-11.

3. Kamran, T.; Samreen, M.; UL Ain, Q. A Generalization of b-metric space and some fixed point theorems. Mathematics 2017, 5, 19. [CrossRef]

4. Abdeljawad, T.; Mlaiki, N.; Aydi, H.; Souayah, N. Double controlled metric type spaces and some fixed point results. Mathematics 2018, 6, 320. [CrossRef]

5. Mlaiki, N.; Aydi, H.; Souayah, N.; Abdeljawad, T. Controlled metric type spaces and the related contraction principle. Mathematics 2018, 6, 194. [CrossRef]

6. Branciari, A. A fixed point theorem of Banach-Caccippoli type on a class of generalised metric spaces. Publ. Math. Debr. 2000, 57, 31-37.

7. Asim, M.; Imdad, M.; Radenović, S. Fixed point results in extended rectangular b-metric spaces with an application. UPB Sci. Bull. Ser. A 2019, 20, 43-50.

8. George, R.; Radenović, S.; Reshma, K.P.; Shukla, S. Rectangular b-metric space and contraction principles. J. Nonlinear Sci. Appl. 2015, 8, 1005-1013. [CrossRef]

9. Sarma, I.R.; Rao, J.M.; Rao, S.S. Contractions over generalized metric spaces. J. Nonlinear Sci. Appl. 2009, 2, 180-182. [CrossRef]

10. Samet, B. Discussion on "A fixed point theorem of Banach-Caccioppoli type on a class of generalized metric spaces" by A. Branciari. Publ. Math. Debr. 2010, 76, 493-494.

11. Suzuki, T. Generalized metric spaces do not have the compatible topology. Abstr. Appl. Anal. 2014, 2014. [CrossRef]

12. Jungck, G. Commuting mappings and fixed points. Am. Math. Mon. 1976, 83, 261-263. [CrossRef]

13. Dung, N.V.; Hang, V.T.L. On relaxations of contraction constants and Caristi's theorem in b-metric spaces. J. Fixed Point Theory Appl. 2016, 1, 267-284. [CrossRef]

14. Mitrović, Z.D.; Radenović, S. A common fixed point theorem of Jungck in rectangular b-metric spaces. Acta Math. Hungr. 2017, 15, 401-407. [CrossRef]

(C) 2019 by the authors. Licensee MDPI, Basel, Switzerland. This article is an open access article distributed under the terms and conditions of the Creative Commons Attribution (CC BY) license (http:/ / creativecommons.org/licenses/by/4.0/). 